\title{
Risk of fall in patients with COPD
}

\author{
Ali Hakamy, ${ }^{1,2}$ Charlotte E Bolton, ${ }^{1}$ Jack E Gibson, ${ }^{2}$ Tricia M McKeever ${ }^{2}$
}

- Additional material is published online only. To view please visit the journal online (http://dx.doi.org/10.1136/ thoraxjnl-2017-211008).

${ }^{1}$ Nottingham Respiratory Research Unit, NIHR

Nottingham BRC, School of Medicine, University of Nottingham, Nottingham, UK ${ }^{2}$ Division of Epidemiology and Public Health, School of Medicine, University of Nottingham, Nottingham, UK

Correspondence to

Dr Tricia M McKeever, Division of Epidemiology and Public Health, School of Medicine, University of Nottingham, Nottingham NG5 1PB, UK;

tricia.mckeever@nottingham. ac.uk

Received 6 September 2017 Revised 19 February 2018 Accepted 26 February 2018 Published Online First 21 March 2018

Check for updates

To cite: Hakamy A, Bolton CE, Gibson JE, et al.

Thorax 2018;73:1079-1080.

\section{ABSTRACT}

A matched cohort study was conducted to determine the incidence of falls in patients following a diagnosis of COPD using a UK primary care database. 44400 patients with COPD and 175545 non-COPD subjects were identified. The incidence rate of fall per 1000 personyears in patients with COPD was higher $(44.9 ; 95 \% \mathrm{Cl}$ 44.1 to 45.8) compared with non-COPD subjects (24.1; $95 \% \mathrm{Cl} 23.8$ to 24.5$)(\mathrm{P}<0.0001)$. Patients with COPD were $55 \%$ more likely to have an incident record of fall than non-COPD subjects (adjusted HR, 1.55; $95 \% \mathrm{Cl}$ 1.50 to 1.59). The greater falls risk in patients with COPD needs consideration and modifiable factors addressed.

\section{INTRODUCTION}

The morbidity and mortality associated with COPD pose a public health challenge with a high economic burden. ${ }^{1}$ The prevalence of falls has been reported to be greater among patients with COPD. ${ }^{2}$ Two previous small studies, both $<100$ subjects, reported almost half of the patients had fallen in the preceding year. ${ }^{34}$

Risk of falls usually encompasses the complex interaction of several risk factors ${ }^{5}$; some of which are common, if not more problematic, in patients with COPD, including impaired balance control and skeletal muscle dysfunction. ${ }^{36}$ There is little consideration of falls risk in COPD in guidelines. ${ }^{57}$ The purpose of this study was to determine the incidence of coded recording of a fall in patients following a diagnosis of COPD in a matched cohort study within The Health Improvement Network (THIN) primary care database in the UK.

\section{METHODS}

The study population comprised individuals aged $\geq 35$ years who had a new diagnosis of COPD between 1 January 2000 and 4 May 2014. The index date was the date of the first recorded COPD diagnosis. Up to four non-COPD individuals were matched with each patient with COPD based on sex, age within 1 year of the index date and general practice, and were assigned the same index date as their matched cases.

Potential confounders included age $(<65$, $65-79, \geq 80$ years old), gender and socioeconomic status (quintile of the Townsend Index of Deprivation). Clinical covariates included the most recent body mass index (BMI) (categorised as $\mathrm{BMI} \leq 20$, BMI $>20 \mathrm{~kg} / \mathrm{m}^{2}$ or missing), most recent cigarette smoking status (never, ex-smoker, smoker, unknown), and history of any of the following fall risk factors before the index date including but not limited to sight impairment, depression, cerebrovascular accident, heart failure, peripheral vascular disease, coronary heart disease, arrhythmia, dizziness and dementia. ${ }^{5}$ Recorded medications that were considered as fall risk factors were also identified; these included but not limited to sedatives, diuretics and antidepressants. ${ }^{5}$ More details are described in the online supplementary material (OLS). Medication episodes were constructed for each participant, and the exposure time was divided into periods of non-exposed periods and exposed periods. Exposed periods were started from the medication dispensing date until the first gap of more than 90 days between prescriptions. Medications started within 90 days prior to the index date were considered within the exposed period. Records of medications initiated more than 90 days prior to the index date were not considered in the analysis.

The demographic and clinical characteristics of the patients with COPD and non-COPD subjects were examined using $\chi^{2}$ tests. The first recorded fall event following the index date was considered. Multivariable Cox proportional hazard model was used to evaluate the association between COPD and fall, as well as a complete case analysis. Person-time commenced at the index date and ended when a fall was experienced or when patients died or left a contributing general practice, whichever occurred first. Each of the confounders that changed the association between fall and COPD by 5\% was included in multivariate Cox regression model, which allowed for the matched cohort. Data management and statistical analysis were performed using Stata V.13.

\section{RESULTS}

The study included 44400 patients diagnosed with COPD and 175545 non-COPD subjects. COPD and non-COPD subjects had similar median follow-up time (median 4.2 years, IQR 1.8-7.4; and median 4.1 years, IQR 1.7-7.5, respectively). The clinical features of the study population are presented in table 1 (further details in the online supplementary material (OLS)). The population had a mean (SD) age of 66.8 (11.4) years, and 53\% were men. Of patients with COPD, $37 \%$ were current smokers, as were $15 \%$ of the non-COPD subjects. Of the patients with COPD, $10646(24 \%)$ had a doctor-recorded fall after the index date, compared with 22117 (12\%) of the non-COPD subjects. The incidence rate of fall in patients with COPD was 44.9 per 1000 personyears $(95 \% \mathrm{CI} 44.1$ to 45.8$)$ and in non-COPD subjects was 24.1 per 1000 person-years $(95 \% \mathrm{CI}$ 23.8 to 24.5 ). The time to first recorded fall was significantly different between the patients with COPD and non-COPD subjects $(\mathrm{P}<0.0001)$ (figure 1). Patients with COPD were $47 \%$ more likely to have a record of incidence of fall than non-COPD subjects (adjusted HR (aHR), 1.47; 95\% CI 1.43 to 1.51 ), after adjusting for smoking 


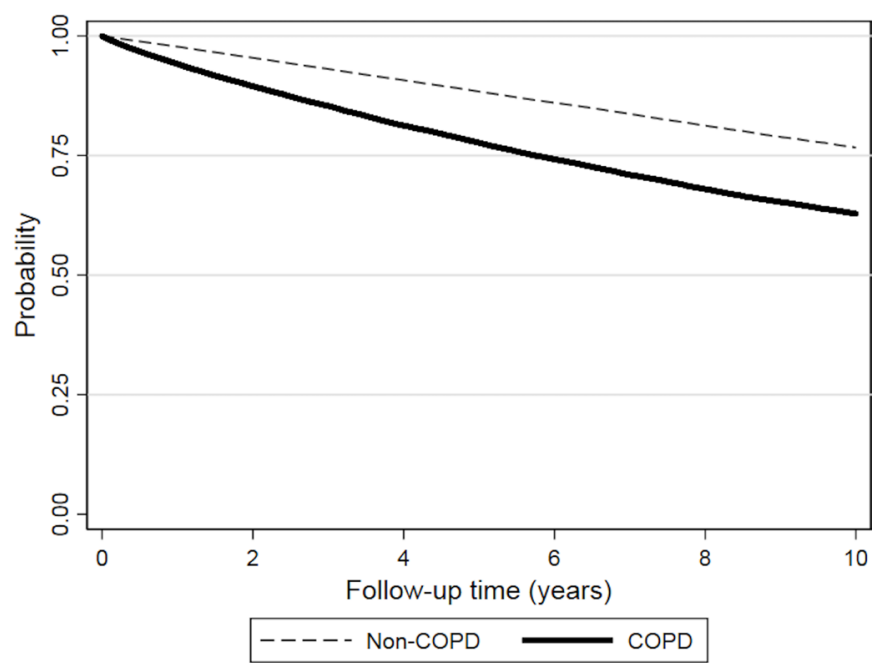

Figure 1 Kaplan-Meier analysis of incidence of time to first fall in patients with COPD and non-COPD.

status, use of antidepressants and diuretics. In the complete case analysis the results were similar $(n=39681$ COPD vs 144058 non-COPD, aHR 1.55 ; 95\% CI 1.50 to 1.59 ) after adjusting for the same confounders.

\section{DISCUSSION}

The coded incidence rate of falls was significantly greater among patients with COPD compared with non-COPD subjects from the THIN primary care database, even after consideration of adjustment for age, gender and other confounding factors. This was the

\begin{tabular}{|c|c|c|}
\hline Characteristics & COPD, $n=44400$ & Non-COPD, $n=175545$ \\
\hline $\begin{array}{l}\text { Age at diagnosis, mean (SD) } \\
\text { years }\end{array}$ & $67.1(11.4)$ & $66.8(11.4)$ \\
\hline \multicolumn{3}{|l|}{ Gender, n (\%) } \\
\hline Male & $23509(52.9)$ & $92981(52.9)$ \\
\hline Female & 20891 (47.1) & 82564 (47.1) \\
\hline \multicolumn{3}{|l|}{ Townsend quintile, n (\%) } \\
\hline 1 least deprived & $6890(15.5)$ & $39167(22.3)$ \\
\hline 2 & $7585(17.1)$ & $37957(21.6)$ \\
\hline 3 & $8937(20.1)$ & $34992(19.9)$ \\
\hline 4 & $10297(23.1)$ & $32518(18.5)$ \\
\hline 5 most deprived & $9222(20.7)$ & $24787(14.1)$ \\
\hline Not recorded & $1472(3.3)$ & $6124(3.5)$ \\
\hline \multicolumn{3}{|l|}{ Most recent smoking status, $\mathrm{n}(\%)$} \\
\hline Never & $4773(10.7)$ & $84184(47.9)$ \\
\hline Ex & $21983(49.5)$ & $55599(31.7)$ \\
\hline Current & $16497(37.1)$ & $27349(15.6)$ \\
\hline Not recorded & $1147(2.5)$ & $8424(4.7)$ \\
\hline \multicolumn{3}{|c|}{ Most recent body mass index, $\mathrm{n}(\%)$} \\
\hline$\leq 20 \mathrm{~kg} / \mathrm{m}^{2}$ & $5578(12.5)$ & $9541(5.4)$ \\
\hline$>20 \mathrm{~kg} / \mathrm{m}^{2}$ & $36722(82.7)$ & $149065(84.8)$ \\
\hline Not recorded & $2100(4.7)$ & 16939 (9.6) \\
\hline
\end{tabular}

first study that investigated the incidence of falls in patients with COPD and which considered other fall risk factors.

A number of factors likely to contribute to falls in the elderly are of even more relevance in patients with COPD. These include impaired balance and skeletal muscle dysfunction, ${ }^{89}$ but might also include cognition, tremulousness and vision, and skeletal muscle dysfunction. ${ }^{57}$ Given the high incidence of fall in COPD and the consequences of falls on mobility, quality of life and injury-related mortality, ${ }^{10}$ assessment of falls risk is important to identify modifiable factors.

A strength of this study is that the primary care data are a large, representative sample cohort of patients with COPD within the UK. However, the actual incidence of falls might be underestimated because of the possibility that patients who experienced minor fall may not have reported to the general practitioner, and some incidence might not be recorded or recorded as free text. Another limitation is that this study is based on READ-coded COPD diagnosis. READ-coded spirometry confirmation at time of diagnosis is not consistently available. Finally, this analysis focused on the first recorded fall and does not consider repeat falls for the same patient.

To conclude, the study demonstrated an increased risk of recorded falls in patients with incident diagnosis of COPD. Further falls risk assessment might be indicated in patients with COPD with opportunity to address modifiable factors.

Contributors $\mathrm{AH}$ was involved in study design, performed the majority of data processing and analysis, and drafted the article. CEB and TMM devised the original idea and contributed to the design of the study and analysis of the data. JEG contributed to the initial stages of data organisation. All authors were involved in drafting and revising the research letter and approved the letter before submission. CEB and TMM are guarantors.

Funding The authors have not declared a specific grant for this research from any funding agency in the public, commercial or not-for-profit sectors.

Competing interests None declared.

Ethics approval The Cegedim Strategic Data Medical Research Scientific Review Committee (14-066).

Provenance and peer review Not commissioned; externally peer reviewed.

(c) Article author(s) (or their employer(s) unless otherwise stated in the text of the article) 2018. All rights reserved. No commercial use is permitted unless otherwise expressly granted.

\section{REFERENCES}

1 Global Initiative for Chronic Obstructive Lung Disease. The global strategy for the diagnosis, management and prevention of COPD. Secondary the global strategy for the diagnosis, management and prevention of COPD. 2017. http://goldcopd.org

2 Lawlor DA, Patel R, Ebrahim S. Association between falls in elderly women and chronic diseases and drug use: cross sectional study. BMJ 2003;327:712-7.

3 Beauchamp MK, Hill K, Goldstein RS, et al. Impairments in balance discriminate fallers from non-fallers in COPD. Respir Med 2009;103:1885-91.

4 Hellström K, Vahlberg B, Urell C, et al. Fear of falling, fall-related self-efficacy, anxiety and depression in individuals with chronic obstructive pulmonary disease. Clin Rehabil 2009:23:1136-44.

5 National Institute for Clinical Excellence. Falls in older people: assessing risk and prevention. Secondary falls in older people: assessing risk and prevention. 2013. https://www.nice.org.uk/guidance/cg161/chapter/introduction

6 Roig M, Eng JJ, Road JD, et al. Falls in patients with chronic obstructive pulmonary disease: a call for further research. Respir Med 2009;103:1257-69.

7 National Clinical Guideline Centre UK. Chronic obstructive pulmonary disease: Management of chronic obstructive pulmonary disease in adults in primary and secondary care, 2010.

8 Hakamy A, Bolton CE, McKeever TM. The effect of pulmonary rehabilitation on mortality, balance, and risk of fall in stable patients with chronic obstructive pulmonary disease. Chron Respir Dis 2017;14:54-62.

9 Swallow EB, Reyes D, Hopkinson NS, et al. Quadriceps strength predicts mortality in patients with moderate to severe chronic obstructive pulmonary disease. Thorax 2007;62:115-20.

10 Boyé NDA, Van Lieshout EMM, Van Beeck EF, et al. The impact of falls in the elderly. Trauma 2013;15:29-35. 